\title{
Promover saúde na escola: reflexões a partir de uma revisão sobre saúde escolar na América Latina
}

\author{
Promoting health in school: reflections based on a review \\ of school health in Latin America
}

Juliana Pereira Casemiro ${ }^{1}$

Alexandre Brasil Carvalho da Fonseca ${ }^{1}$

Fabio Vellozo Martins Secco ${ }^{1}$

\footnotetext{
${ }^{1}$ Programa de PósGraduação em Educação em Ciência e Saúde, Laboratório de Estudos da Ciência, Universidade Federal do Rio de Janeiro. Centro de Ciências da Saúde Bloco A/sala 12, Ilha do Fundão. 21.941-972 Rio de Janeiro RJ Brasil.

julianacasemiro@gmail.com
}

\begin{abstract}
This paper presents a bibliographic review on the topic of school health in Latin America based on papers published between 1995 and 2012 and reflects the potential of its implementation as public policy. It was possible to identify the persistence of initiatives centered on disease with a focus on screening and preventive actions. However, the selection of health promotion as the strategic axis of school health has resulted in changes. In this context, the challenges include the definition of roles in the planning and execution of programs and the experience of the broader concept of health. Creating and strengthening spaces for participation with students, teachers, health professionals and the community is indispensable for the creation of fairer and healthier realities.

Key words School health, Schools that promote health, Right to health
\end{abstract}

Resumo Este artigo apresenta revisão bibliográfica sobre o tema da saúde escolar na América Latina a partir de artigos publicados entre 1995 e 2012 e reflete as potencialidades de sua efetivação enquanto política pública. Foi possível identificar a persistência de iniciativas centradas na doença com foco nas ações de triagem e prevenção. Contudo, a eleição da promoção da saúde como eixo estratégico da saúde escolar tem impulsionado mudanças. Neste contexto, são desafios a definição de papéis no planejamento e execução de programas e a vivência do conceito ampliado de saúde. Criar e fortalecer espaços de participação com estudantes, professores, profissionais de saúde e comunidade é indispensável para a construção de realidades mais justas e saudáveis.

Palavras-chave Saúde escolar, Escolas promotoras de saúde, Direito à saúde 


\section{Introdução}

Não é de hoje que se reconhece o vínculo entre a saúde e a educação. Sob o argumento desta íntima ligação entre as duas áreas existe ao menos um consenso: bons níveis de educação estão relacionados a uma população mais saudável assim como uma população saudável tem maiores possibilidades de apoderar-se de conhecimentos da educação formal e informal. Dependendo do local de onde se fala e de quais tintas são usadas encontram-se os mais diferentes discursos e cenários ou, dito de outra forma, sob aquele argumento cabem as mais diversas abordagens ao tema.

A escola tem representado um importante local para o encontro entre saúde e educação abrigando amplas possibilidades de iniciativas tais como: ações de diagnóstico clínico e/ou social estratégias de triagem e/ou encaminhamento aos serviços de saúde especializados ou de atenção básica; atividades de educação em saúde e promoção da saúde.

Estas iniciativas têm sido identificadas sob o termo saúde escolar utilizado para designar ações que objetivam "proporcionar condições adequadas à realização do processo educacional que requer condições mínimas de saúde"'. Enquanto termo descritor em Ciências da Saúde são caracterizadas como àquelas "voltadas para a comunidade escolar para concretização das propostas de promoção da saúde. [...] desenvolvendo ações para a prevenção de doenças e para o fortalecimento dos fatores de proteção"2.

Desde os trabalhos de Johann Peter Frank (1745-1821), médico alemão considerado o "pai da saúde escolar"3 e de reconhecida relevância para a constituição do campo da Saúde Pública, até as iniciativas mais recentes muitas coisas mudaram. Contudo, a identificação do espaço escolar como lócus fundamental de prevenção de doenças e promoção da saúde permanece.

Como extremos numa linha do tempo, podese afirmar que o ponto de partida seria o da identificação da escola como espaço de disseminação de regras de civilidade e normas de higiene calcadas no ideal higienista dos séculos XIX e XX. No outro extremo temporal, os debates mais recentes dariam conta de pautar a escola como local de promoção da saúde.

No cenário latino-americano, marcado por desigualdades históricas e constrangedoras, os dados oficiais demonstram melhoras dos indicadores sociais e de saúde apesar da manutenção de grandes desafios ${ }^{4,5}$. Com relação especifica- mente às estatísticas da educação identificam-se progressos na universalização do acesso ao ensino fundamental persistindo, no entanto o baixo investimento dos governos. Isto resulta em condições inadequadas de trabalho e de salário para os professores o que impacta na possibilidade de construção de escolas de qualidade para todos ${ }^{6}$. Importante ainda ressaltar a existência de um debate extenso sobre desigualdades e assimetrias na região no que se refere aos sistemas educacionais e sobre a necessária construção de compromisso ético-político para recuperar o sentido social e cultural da educação na perspectiva de que esta torne-se "mais justa e igualitária, mais democrática e participativa" em toda a América Latina ${ }^{7}$.

Para a OPAS a constatação de que uma parcela maior de crianças latino-americanas tem hoje acesso à educação formal reforça o argumento de promover saúde na escola ${ }^{4}$. Importantes sistematizações e direcionamentos ocorreram a partir da criação da Rede Latino-Americana de Escolas Promotoras de Saúde durante o Congresso de Saúde Escolar no Chile, em 1995. A partir de então tal estratégia representa a opção para a institucionalização e conformação de políticas públicas de saúde escolar incentivada pela OPAS. A Iniciativa de Escolas Promotoras de Saúde (EPS) corresponde a:

estratégia de promoção da saúde no âmbito escolar e um mecanismo articulado de esforços e recursos multissetoriais, orientados para o melhoramento das condições de saúde e bem-estar, ampliando assim as oportunidades para um aprendizado de qualidade e o desenvolvimento humano sustentável, para todos os integrantes das comunidades educativas.

Diante do exposto, este artigo tem como objetivo apresentar uma revisão bibliográfica sobre saúde escolar na América Latina a partir de artigos publicados entre os anos de 1995 e 2012, refletindo o tema a partir das possibilidades de sua efetivação enquanto política pública.

\section{Procedimentos metodológicos}

Para Deslandes ${ }^{8}$ a pesquisa bibliográfica precisa ser: disciplinada porque é prática sistemática realizada diante de critérios claros de escolha; crítica porque estabelece diálogo reflexivo entre a teoria e outros trabalhos com o mesmo objeto de investigação; e ampla para permitir o contato com o estado de conhecimento sobre determinado problema. Constitui, segundo Minayo ${ }^{9}$, etapa 
essencial a toda pesquisa por ser "capaz de projetar luz e permitir uma ordenação ainda imprecisa da realidade empírica"9.

Este artigo integra uma pesquisa de doutorado que busca refletir limites e possibilidades da prática de educação alimentar e nutricional no âmbito do Programa Saúde na Escola (PSE). Desta forma, partindo de uma ampla "moldura" representada por um conjunto de artigos sobre saúde escolar, chega-se a um subconjunto que representa o objeto desta revisão: a saúde escolar enquanto política pública na América Latina.

A revisão apresentada foi realizada a partir de pesquisa dos artigos produzidos entre 1995 a 2012 na América Latina disponíveis nas bases de on line Scielo e Lilacs BVS em janeiro de 2013. As buscas foram conduzidas a partir das expressões Escolas Promotoras de Saúde, saúde escolar, saúde na escola, Programa Saúde na Escola, Escuelas Promotoras de Salud, salud en la escuela, Programa de Salud Escolar, Health Promoting Schools e School Health.

Foram definidos como critérios de inclusão inicial os artigos referentes a iniciativas e pesquisas realizadas no ambiente escolar ou que referiam algum vínculo com escolas - como, por exemplo, encaminhamento escolar para serviços de saúde ou de diagnóstico. Foram excluídos os artigos cujos resumos não foram localizados e aqueles que se referiam apenas a crianças em "idade escolar" e não necessariamente à escola.
Os dados foram coletados a partir dos resumos e de artigos completos disponíveis nas bases de dados. Quando necessário foi efetuada a busca dos artigos diretamente nas versões on line das revistas ou através da ferramenta de busca Google. Ainda assim, não foi possível acessar resumos de 19 trabalhos.

Foram localizados 440 artigos dos quais 54 foram excluídos, a partir dos critérios acima descritos, totalizando 386 trabalhos analisados. Dentre estes últimos foram por fim identificados os 43 artigos que tratavam de iniciativas de institucionalização de ações de saúde escolar enquanto política pública para a realização de uma síntese. Informações relevantes à revisão foram inseridas em planilha de Excel a fim de facilitar visualização e análises.

De forma complementar, foram utilizadas publicações oficiais do mesmo período para fomentar e contextualizar as reflexões a partir dos referidos artigos (Gráfico 1).

\section{Saúde escolar: quais experiências?}

Grande parte dos artigos localizados corresponde a trabalhos desenvolvidos no Brasil (241 artigos), seguido por Chile (32), Colômbia (20) e Argentina (18). Os outros artigos tiveram como origem Cuba, Honduras, Venezuela, Peru, México, Costa Rica, Equador, Uruguai, Jamaica, Barbados.

Em 274 artigos os estudantes compuseram as amostras ou foram sujeitos da pesquisa. Pro-

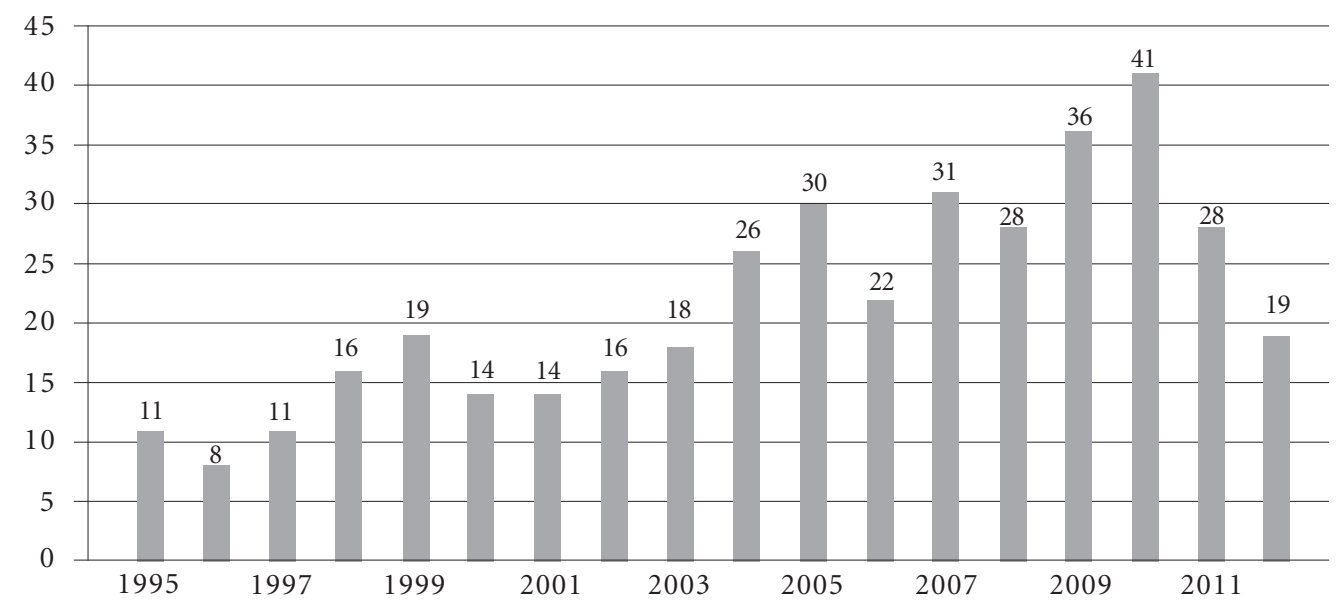

Gráfico 1. Número de artigos publicados sobre "Saúde Escolar” na América Latina entre os anos de 1995 a 2012. 
fessores, profissionais da escola e gestores da educação, profissionais de saúde, responsáveis, familiares e comunidade fizeram parte de pesquisas que, em alguns casos, combinaram estes em diferentes composições de amostras.

Observando o número de publicações por ano no período da revisão percebe-se um comportamento crescente que obtém seu ápice em 2010 com 41 artigos publicados.

Considerando que parcela importante dos artigos foram trabalhos realizados no Brasil cabe registrar que os debates brasileiros sobre EPS iniciaram concomitantemente aos debates latino-americanos, contudo maior ênfase foi dada a partir da publicação da Portaria Interministerial no $749 / 2005^{10}$ que constitui a Câmara Intersetorial com a finalidade de subsidiar a Política Nacional de Educação em Saúde na Escola. No contexto brasileiro o Programa de Saúde na Escola (PSE), instituído pelo Decreto Presidencial $\mathrm{n}^{\circ} 6.286 / 2007^{11}$, representa a atual estratégia de saúde escolar. Com relação à alimentação escolar, o país conta com política pública para este fim desde a década de 1950, contudo através da Lei $n^{\circ} 11.947 / 2009^{12}$ - que define o Programa Nacional de Alimentação Escolar (PNAE) - o direito à alimentação escolar é afirmado como universal e vinculado às estratégias de promoção da saúde na escola.

Os artigos sobre alimentação e nutrição, atividade física e doenças cardiovasculares foram os mais numerosos (Gráfico 2). Os debates sobre alimentação e nutrição incluíram como subitens a desnutrição e as carências nutricionais (hipovitaminose A e anemia ferropriva). Contudo, constatou-se crescente associação da alimentação e nutrição com os temas da promoção da atividade física e do diagnóstico da obesidade e de doenças crônicas não transmissíveis, por isto foi feita a opção de agrupar tais temas.

O grande número de artigos reflete a mudança de perfil epidemiológico e nutricional observada na América Latina, com a sobreposição de padrões: das doenças da falta versus doenças do excesso alimentar - a chamada dupla carga da má nutrição. Além disto, os dados da OPAS informam que os refeitórios escolares foram relatados por vários países como estratégia de saúde escolar, ressaltando-os como oportunidade para a realização de ações relacionadas com a nutrição e hábitos alimentares ${ }^{4}$.

Os demais artigos corresponderam a trabalhos nas áreas de saúde bucal; doenças parasitárias, transmissíveis e respiratórias; oftalmologia; prevenção e tratamento do uso de álcool, drogas e tabaco; e saúde sexual e reprodutiva (Gráfico 2).

No grupo de doenças parasitárias, transmissíveis e respiratórias houve destaque para verminoses, dengue, asma e pediculose, temas já tradicionais em termos de saúde escolar. No grupo "outros temas" foram agrupados trabalhos com objetos variados tais como: dor recorrente, distúrbio do sono, epilepsia, ensino de enfermagem, atuação do pediatra, entre outros.

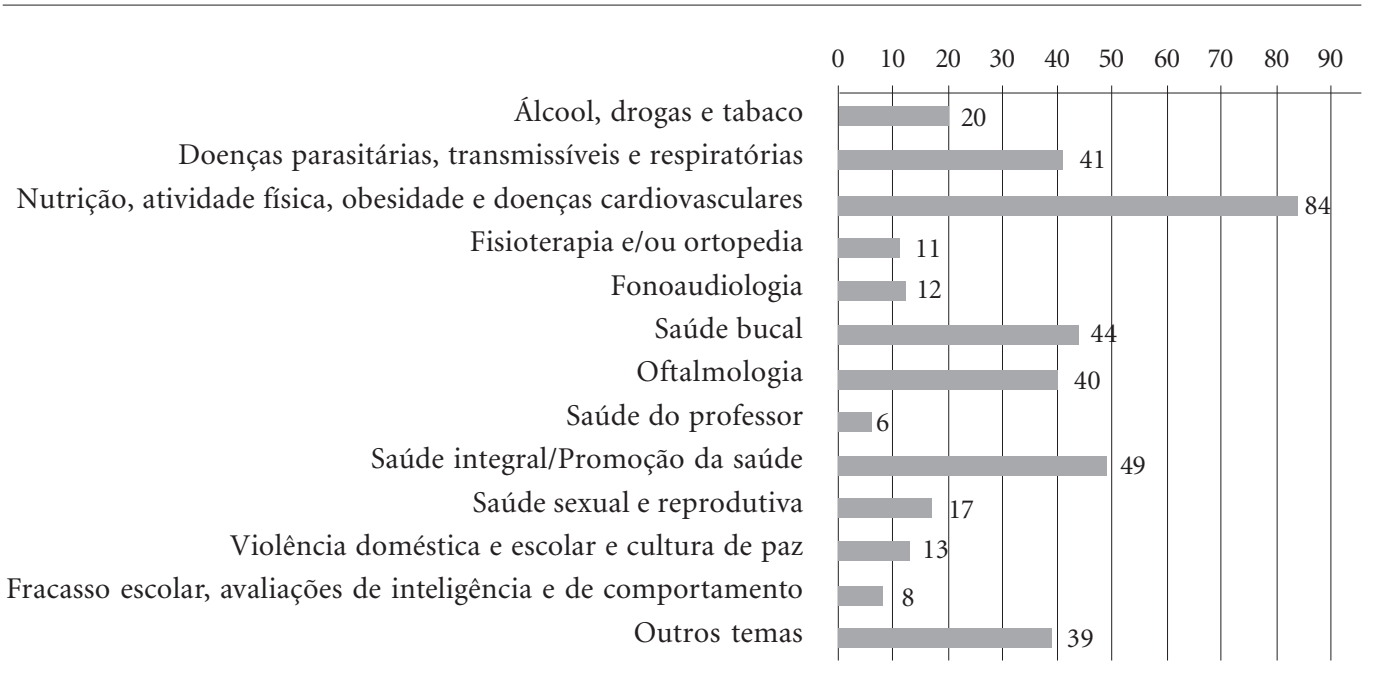

Gráfico 2. Distribuição segundo áreas ou temas de interesse dos artigos sobre "Saúde Escolar" na América Latina entre os anos de 1995 a 2012. 
Os diagnósticos coletivos (avaliações clínicas e/ou ações de triagem) foram apresentados em 169 artigos. A abrangência de tais artigos foi bastante variada: desde diagnósticos restritos a um conjunto de alunos, uma ou mais escolas até os mais amplos abarcando municípios inteiros ou estudos de base nacional. A grande interrogação a partir do exame das conclusões dos artigos acerca de diagnóstico coletivo é sobre o quanto estes trabalhos são desenvolvidos com um fim em si mesmo, ou seja, ao final avaliam positivamente um método ou descrevem a população e recomendam a repetição dos procedimentos utilizados.

Desta forma, desdobramentos práticos ou encaminhamentos políticos das demandas levantadas simplesmente não fazem parte de suas pautas e não se incorpora um elemento básico de vigilância em saúde: informação para ação. Assim, contata-se que ainda são realizadas ações de saúde escolar em que a escola é apenas cenário de pesquisa e objeto de iniciativas centradas na doença. Os dados não retornam aos sujeitos ou à realidade pesquisada.

Ações de diagnóstico social e/ou triagem clínica que se desenvolvem isoladamente, ou seja, fora de um plano de intervenções apontam as precariedades da escola ou do ambiente familiar e comunitário como obstáculos intransponíveis ou simplesmente citam tais precariedades como as causas dos diagnósticos desfavoráveis. Houve uma recorrência deste tipo de conclusão uma vez que grande parcela destes estudos foi realizada em áreas pobres, com grande vulnerabilidade social.

Importante frisar que qualquer ação de produção de conhecimento está revestida de intencionalidade política, mesmo que não haja uma expressão clara disto. Como bem alertou o educador Paulo Freire, todos aqueles que adentram territórios marcados pela traição do "direito de ser mais" devem compreender "o futuro como problema e não como inexorabilidade" e acrescentou:

É por isso também que não me parece possivvel nem aceitável a posição ingênua ou, pior, astutamente neutra de quem estuda, seja o físico, o biólogo, o sociólogo, o matemático, ou o pensador da educação. Ninguém pode estar no mundo, com o mundo e com os outros de forma neutra. Não posso estar no mundo de luvas nas mãos constatando apenas $^{13}$.

Houve uma parcela dos artigos que abordou de forma mais ampla a saúde escolar, incorpo- rando os referenciais da saúde integral e da promoção da saúde. Estes apresentaram possibilidades de se repensar tanto a pesquisa como as ações de saúde na escola de forma mais participativa, envolvendo profissionais tanto da saúde como da educação, corpo docente e discente, gestores e comunidades.

Por fim, é importante registrar que a maioria dos artigos refere-se a pesquisas em instituições ou órgãos da administração pública - sejam secretarias de educação, creches, institutos de ensino, e escolas municipais ou estaduais. Algumas das experiências relatadas mencionaram trabalho concomitante e/ou comparativo entre instituições públicas e privadas. Pequena parte dos artigos apresentou resultados de intervenções e pesquisa em escolas particulares. Contudo, isto não significa que os trabalhos tenham estabelecido vínculo com debates acerca de políticas públicas.

Segundo Höfling ${ }^{14}$ as políticas públicas referem-se à ação que o Estado desenvolve através de programas e projetos de governo destinados a setores da sociedade. O Estado assume desta forma sua responsabilidade de envolver órgãos públicos e organismos da sociedade na implementação destas políticas.

Tendo por base esta definição, foram selecionados 45 artigos relacionados à incorporação da saúde escolar enquanto política pública em países latino-americanos, sintetizados no Quadro 1.

Identifica-se um panorama amplo e diversificado de ações e debates desenvolvidos em torno da saúde escolar como política pública que envolve iniciativas municipais e nacionais. São ações promovidas exclusivamente pelos governos ou em parceria com universidades e com instituições da sociedade civil organizada. Reúnem intervenções e reflexões relacionadas ao processo de implementação de estratégia de programas de promoção da saúde em escolas e outros temas como: prevenção e controle de dengue, saúde bucal, alimentação escolar, controle da obesidade, suplementação de vitamina A em escolas, prevenção do uso de tabaco, álcool e outras drogas, saúde sexual e reprodutiva e cuidado oftalmológico.

Chamou atenção a ocorrência de diversos relatos e recomendações relacionados à formação em saúde escolar para profissionais de saúde e educação articulada às ações de educação em saúde. O professor é o profissional mais citado neste aspecto. Foram descritas também iniciativas de formação de jovens estudantes como multiplicadores de informação. 
Quadro 1. Síntese de artigos relacionados a políticas públicas de "Saúde Escolar” publicados na América Latina - 1995 a 2012.

\begin{tabular}{|c|c|}
\hline País & Síntese \\
\hline Argentina & $\begin{array}{l}\text { Foram publicados } 03 \text { (três) artigos entre } 2007 \text { e 2009. A partir da descrição e avaliação de } \\
\text { experiências com promoção de saúde em escolas de Buenos Aires, apresentam debates } \\
\text { teóricos acerca de categorias relevantes ao tema tais como: concepções de saúde, } \\
\text { empowerment, autonomia, noção de sujeito e formação de professores. }\end{array}$ \\
\hline Brasil & $\begin{array}{l}\text { Foram publicados } 24 \text { artigos entre } 1995 \text { e } 2012 \text {. Os artigos apresentam revisões da } \\
\text { literatura e da legislação nacional acerca do tema saúde escolar, do Programa Saúde na } \\
\text { Escola e Programa Nacional de Alimentação Escolar e políticas públicas de alimentação e } \\
\text { nutrição e combate à obesidade infantil. Descrevem e avaliam experiências municipais de } \\
\text { promoção da saúde na escola e alimentação escolar. Tratam de experiências de diagnóstico } \\
\text { clínico e triagem em saúde bucal, oftalmologia, avaliação nutricional e uso de álcool e } \\
\text { drogas. Apresentam avaliação e reflexão sobre ações de educação em saúde (diferentes } \\
\text { concepções). Sistematizam avanços e desafios das propostas locais e nacionais de } \\
\text { promoção da saúde na escola. }\end{array}$ \\
\hline Chile & $\begin{array}{l}\text { Foram publicados } 09 \text { artigos entre } 1998 \text { e } 2011 \text {. Descrevem e avaliam experiências } \\
\text { chilenas de atuação em saúde escolar em temas variados: saúde sexual e reprodutiva, } \\
\text { formação de professores, oftalmologia, saúde bucal, programa de alimentação escolar, } \\
\text { saúde e nutrição e combate à obesidade. Recomendam ampliar investimentos e } \\
\text { desenvolver ações sistemáticas em políticas públicas de alimentação e nutrição. } \\
\text { Apresentam estudos epidemiológicos sobre saúde bucal e oftalmologia. Avaliam a eficácia } \\
\text { de estratégia educativa de combate à obesidade. }\end{array}$ \\
\hline Colômbia & $\begin{array}{l}\text { Foram publicados } 04 \text { artigos entre } 2002 \text { e 2010. Apresentam experiências colombianas } \\
\text { em promoção da saúde na escola denominadas neste país como Estrategia Escuelas } \\
\text { Saludables. A partir das descrições avaliam estratégias de implementação e discutem } \\
\text { intersetorialidade. Em um dos artigos descreve e avalia estratégia de educação nutricional. }\end{array}$ \\
\hline Cuba & $\begin{array}{l}\text { Foram publicados } 02 \text { (dois) artigos em } 2004 \text { e } 2007 \text {. O primeiro artigo descreve e avalia } \\
\text { intervenção nacional de suplementação de vitamina A para escolares em regime de } \\
\text { internato. O segundo trata da descrição e reflexão acerca da proposta cubana de promoção } \\
\text { da saúde na escola. }\end{array}$ \\
\hline Honduras & $\begin{array}{l}\text { O artigo publicado em } 2012 \text { descreve um programa de controle e prevenção de dengue em } \\
\text { professores e estudantes passam por processo de formação para realizarem junto com } \\
\text { acadêmicos e profissionais de saúde visitas domiciliares. É uma iniciativa da universidade } \\
\text { com organizações da sociedade civil que buscou apoio governamental. A dificuldade de } \\
\text { envolvimento do governo é destacada como principal limite. }\end{array}$ \\
\hline Perú & $\begin{array}{l}\text { O artigo publicado em } 2009 \text { apresenta a avaliação de experiência de promoção da saúde } \\
\text { em duas escolas peruanas. Localiza tal experiência dentro das estratégias de promoção da } \\
\text { saúde desenvolvidas pelo Ministério da Saúde desde } 2002 \text {. }\end{array}$ \\
\hline Venezuela & $\begin{array}{l}\text { O artigo publicado em } 2004 \text { apresenta a avaliação de programa de saúde bucal realizado } \\
\text { em uma instituição pública ligada ao Ministério da Educação e Cultura. Esta avaliação } \\
\text { envolve profissionais de saúde, professores, escolares e mães. Identifica abordagem de } \\
\text { saúde centrada no risco e dificuldade em envolver as mães em oficinas. }\end{array}$ \\
\hline
\end{tabular}

\section{Saúde escolar: o que representa a opção pela promoção da saúde?}

Como afirmado anteriormente, a Iniciativa de Escolas Promotoras de Saúde foi eleita como estratégia prioritária para o desenvolvimento de ações de saúde escolar na América Latina. Ela reúne três componentes: educação para a saúde com enfoque integral; criação e manutenção de entornos e ambientes saudáveis; provisão de serviços de saúde, nutrição saudável e vida ativa ${ }^{4}$.

A partir de tais orientações governos e sociedade civil têm organizado suas iniciativas e alternativas. Trata-se de uma abordagem pautada nos 
valores da Promoção da Saúde: qualidade de vida, saúde, solidariedade, equidade, democracia, cidadania, desenvolvimento, participação e parceria, entre outros ${ }^{15}$. Contudo, seu processo de implementação não ocorre com a eliminação completa e instantânea dos preceitos anteriormente vigentes, ou seja, a construção de estratégias de promoção da saúde na escola coexiste com ações construídas a partir dos ideais da higiene escolar. O que representa esta opção pelo ideário da promoção da saúde?

Segundo Arouca ${ }^{16}$ o termo Higiene, tomado em seu sentido mais geral e etimológico pode ser traduzido como "arte de conservar a vida". Em termos de aplicação no campo da saúde pública o autor registra que é um conceito que muda a cada época histórica. A "Higiene como Ciência"17 ou como "a aplicação de um conjunto das ciências na manutenção do bem-estar, mito de uma unidade do conhecimento em prol do bem viver"16 teve grande expressão nos séculos XIX e XX e foi apresentada como a solução para problemas não resolvidos pela medicina da época. Alinhou-se às concepções e ideologias liberais justificando a existências de patologias pelos comportamentos individuais e diminuindo desta forma a importância dos aspectos sociais ${ }^{16}$. E como isto se relaciona à escola?

Seguindo o ideário positivista do final do século XIX, a higiene e a educação adentraram ao século XX, consolidadas em seu papel difusor do espírito científico, imprescindivel à regeneração social, mesmo que, em vários momentos, o 'social' ficasse à margem das discussões e as formas ditas higienizadas de viver propostas fossem pouco acessíveis às populações pobres ${ }^{17}$.

O ideário higienista encontrava sintonia com o discurso ideológico corrente que colocava a escola como instituição responsável por modelar certo tipo de cidadão exigido pelos novos tempos e contribuir assim para superação do "atraso" dos países subdesenvolvidos. Pautada na hipótese de que a doença surgia e se mantinha em decorrência da ignorância, a solução seria então a prescrição de normas e regras.

A escola foi lócus privilegiado dessas prescrições, local onde a higiene formatou propostas de construção de modelos educacionais, formação de professores, inspeção de alunos e de organização de espaços e equipamentos, objetivando a formação de novos e higienizados cidadãos ${ }^{17}$.

A escola foi reconhecida como espaço estratégico para a propagação da higiene porque agrupava num mesmo espaço crianças que, sendo concebidas como "massa modelável”, seriam ca- pazes de reproduzir no ambiente familiar as prescrições repassadas pela escola. Em tal conjuntura capacitar professores para atuarem como educadores sanitários tornou-se imprescindível e aos médicos coube o papel de "sensibilizar e treinar" o professor para ser o "coadjuvante da missão higienista" 17 . Os médicos ocupam lugar nas escolas públicas, mas também no corpo docente de Escolas Normais ${ }^{18}$.

E a formação higienista de professores por meio de cursos específicos foi o primeiro passo dado, já que a escola foi escolhida como 'sede primeira' de formação de hábitos higiênicos, corroborando as relações de saúde, educação e seus respectivos representantes $^{17}$.

Afora tudo isto, o discurso higienista apresenta forte identidade com ideais eugênicos e serviu para fornecer hipóteses e justificavas sobre o fracasso escolar. Ao relacionar fracasso escolar à desnutrição, aos distúrbios neurológicos e outras patologias, atribui aos indivíduos e às suas famílias o pesado fardo de culpa e fatalismo ${ }^{18,19}$.

A patologização da educação consiste em um reducionismo biológico, que é explicar a situação e o destino de indivíduos e grupos através de suas características individuais, desse modo esconde os determinantes políticos e pedagógicos do fracasso escolar, isentando de responsabilidades o sistema social vigente e a instituição escolar. Como decorrência dessa concepção, é o indivíduo o maior responsável por sua condição de vida e destino, as circunstâncias sociais e politicas teriam influência mínima ${ }^{18}$.

A partir destas heranças, iniciativas de saúde escolar praticados nas décadas de 1980 e 1990 em países da América Latina restringiram-se a ações para "melhorar condições de higiene e saneamento básico, prevenção de doenças transmissíveis, tratamento de doenças específicas e realização periódica e indiscriminada de exames médicos ou provas de triagem" ${ }^{4}$. Tais ações ocorriam de forma desarticulada, sem explícita identificação de possíveis objetivos estratégicos e políticos e a partir de modelo vertical, "medicalizado" e "assistencialista”.

[...] a saúde da população escolar continuava sendo compreendida mais em termos de ausência de doença, do que como o resultado de um processo de transformação coletiva dos fatores determinantes de saúde e o bem-estar, no qual os profissionais da saúde e todos os membros da comunidade escolar podem e devem converter-se em atores ativos ${ }^{4}$.

É também entre as décadas de 1980 e 1990 que a Promoção da Saúde desponta como opção teórico-metodológica para o estabelecimento de 
políticas públicas de saúde. A Carta de Ottawa (1986) é documento essencial para compreender o contexto de desenvolvimento da Promoção de Saúde que, segundo Buss ${ }^{15}$, é estratégia importante capaz de enfrentar múltiplos problemas de saúde que afetam à população. Nesta lógica, são muitos os espaços e os atores que podem e devem ser acionados para estratégias de promoção da saúde, dentre eles a escola tem sido fortemente destacada. Por este ponto de vista a escola deixa de ser entendida como local de propagação de normas para ser apresentada como:

[...] cenário de caráter formal, em que é possível gerar autonomia, participação crítica e criatividade para a promoção da saúde, que deve, no âmbito escolar, partir da visão integral, multidisciplinar do ser humano, considerando as pessoas em seu contexto familiar, comunitário e social ${ }^{20}$.

Neste sentido, a opção por efetivar as estratégias de promoção da saúde nas escolas significa eleger uma proposta de ação participativa que se desenvolve nas escolas envolvendo a comunidade educativa em um processo de melhoria contínua, visando à criação de condições para uma educação integral que se adapta às características do meio, tornando a escola um lugar agradável para aprender e viver ${ }^{21}$.

Há também mudanças na visão sobre os papéis e as responsabilidades assumidos através das parcerias e articulações em torno das estratégias de promoção da saúde na escola ${ }^{20,22,23}$. Entendese que há necessidade de forte conexão entre escolas e serviços de saúde para favorecer a interconexão de saberes e a participação de ambos a partir de objetivos comuns ${ }^{21}$.

As ações dos profissionais de saúde nas atividades intersetoriais também precisam se distanciar das antigas relações de saúde e educação, é preciso criar vínculos e envolver os professores de forma participativa, respeitando os diferentes saberes $e$ necessidades ${ }^{23}$.

São valorizadas as iniciativas com participação ativa dos estudantes e as atividades de empowerment com objetivo de formar agentes multiplicadores e valorizar o surgimento de líderes entre os próprios jovens $\mathrm{s}^{24,25}$.

A educação em saúde passa a ser proposta a partir de objetivos mais amplos e pautados a partir de diagnósticos locais ${ }^{19}$ assim como as demais ações de saúde escolar.

As atividades em saúde no espaço escolar devem favorecer uma ação mais reflexiva e crítica do conceito de saúde, com investigação de demandase temas pertinentes à comunidade escolar e particularmente aos escolares ${ }^{23}$.
A apresentação de avaliação e descrição de técnicas e metodologias utilizadas em projetos ou ações foi objetivo de diversos artigos. Foram relatados processos de formação com professores e outros profissionais da escola assim como palestras e oficinas realizadas com responsáveis, estudantes e comunidade. Observa-se um leque de ações que inclui estratégias mais tradicionais como palestras, distribuição de cartilhas e panfletos - assim como atividades lúdicas e criativas como círculos de cultura, teatro e contação de história com estudantes e uma experiência de modalidade de educação à distância para professores.

A formação de professores continua a ser tarefa valorizada, mas neste contexto mudam-se seus sentidos e objetivos. O foco da formação inclui conteúdos específicos sobre saúde. Contudo, são pautados, por exemplo, tópicos relacionados à concepção sobre saúde-doença, sobre a importância de que os professores se interessem e se apropriem das questões de saúde que preocupam os jovens e também reflexões sobre a evolução histórica destes problemas relacionando ao seu alcance social atual, as diferentes áreas geográficas e ao campo social ${ }^{24}$.

Ainda há muito que se caminhar para que a mudança de foco da saúde escolar ocorra efetivamente, contudo há uma produção acadêmica e técnica consistente que aponta possibilidades. Como apresentam Santos e Bógus ${ }^{20}$ numa mesma escola podem coexistir, por um lado, percepções e visões higienistas e de isolamento da instituição em relação a outros equipamentos públicos do território e, por outro, práticas e atitudes relacionadas a uma visão ampliada de saúde, considerando aspectos sócio-históricos.

\section{Alguns desafios \\ Promoção da Saúde na Escola}

Nos artigos que apresentam revisões e relatos de experiências pautados nos referenciais de EPS há uma preocupação em enfatizar a participação ampla (profissionais, pais, estudantes e comunidades) nas diversas etapas dos projetos e ações. Há, no entanto, um debate ainda em construção que se refere à definição de papéis e responsabilidades no planejamento e execução de programas de saúde escolar. Este desafio remete a três conceitos que podem e devem ser aprimorados e problematizados na perspectiva de atuação em saúde escolar, são eles: intersetorialidade, interdisciplinaridade e participação. Esta constatação não é uma novidade em termos de políticas de promoção da saúde. 
Sobre o desafio da intesetorialidade Buss ${ }^{15}$ alerta para a necessidade de cuidar para que a proposição de políticas públicas saudáveis não determine condição de subordinação de outros setores governamentais à saúde, com risco de gerar resistência e isolamento.

Tendo na interdisciplinaridade o seu fundamento cognitivo e na intersetorialidade a sua ferramenta operacional, as políticas saudáveis, para não se limitarem a uma normatividade burocrática socialmente natimorta, devem suscitar ou partir de pactos horizontais com parceiros de outros setores governamentais e de outras comunidades epistêmicas, como os urbanistas, os educadores etc ${ }^{15}$.

A intersetorialidade é reconhecida como uma das principais barreiras para a efetivação da EPS na Região, sendo recomendado investir na consolidação de mecanismos formais de coordenação intersetorial ${ }^{4}$.

[...] a ação intersetorial é um processo de aprendizagem e resolução dos atores envolvidos para que a ação integrada responda aos problemas da população de um território definido saindo do limite da necessidade para o da liberdade ${ }^{26}$.

Adotar a intersetorialidade é prática que ultrapassa o simples sentido de um setor buscar apoio para seus objetivos em outro. Na realidade, refere-se a uma mudança de cultura e de forma de organizar políticas públicas para que estas ultrapassem as segmentações dos atuais processos decisórios. Requer integração e coordenação de tais processos de maneira que se garanta à eleição partilhada dos problemas a serem enfrentados, garantia de orçamento, definição de estratégias e objetivos construídos conjuntamente ${ }^{27}$. Trata-se de construir mecanismos sofisticados e eficientes de planejamento que aperfeiçoem a utilização de recursos e permita clareza no acompanhamento de metas e resultados que só se concretizam com efetivo funcionamento de espaços e mecanismos de concertação e diálogo.

As políticas públicas no Brasil e em várias partes do mundo têm sido construídas fortemente setorizadas e compartimentadas. É a constatação de que na vida concreta as necessidades da população aparecem de forma complexa e, muitas vezes, contraditória, que aponta a demanda por estas mudanças nas áreas de planejamento e de gestão orçamentária.

Existem orientações claras da OPAS sobre a relevância de formação de Comissões Nacionais Mistas como mecanismos facilitadores da coordenação intersetorial da estratégia de EPS. Contudo, observa-se que as iniciativas de saúde escolar tendem a ser financiadas e por isso gerenci- adas pelo setor saúde, como demonstram, por exemplo, experiências na Argentina ${ }^{28}$, no Peru $^{29}$ e na Colômbia ${ }^{21}$. Para Ferreira et al. ${ }^{26}$, mesmo a experiência brasileira - com EPS e posteriormente com o PSE - que optou pela constituição de grupos de trabalho/comissão intersetorial nas três esferas de governo, a participação dos setores de saúde e educação não ocorreu de forma equânime. A adesão e o repasse de recurso financeiro acontecem por meio do Ministério da Saúde que exerce maior poder de decisão.

Em 2001 pesquisa com participação de 17 países latino-americanos (Argentina, Bolívia, Brasil, Colômbia, Costa Rica, Cuba, Chile, Equador, El Salvador, Guatemala, Honduras, México, Nicarágua, Paraguai, Peru, República Dominicana e Uruguai) identificou que 94\% desenvolvia ações de promoção de saúde para população em idade escolar e/ou programas de saúde escolar. As políticas relacionadas à estratégia de Escolas Promotoras de Saúde foram mencionadas por $82 \%$ dos países. Contudo, apenas 30\% dos países informaram existência de orçamentos específicos ${ }^{4}$.

As universidades e as organizações da sociedade civil são apresentadas como parceira em muitas experiências, representando por vezes a única fonte de financiamento das ações. Estas parcerias são relevantes e a definição de papéis destes atores no desenvolvimento das estratégias de saúde escolar também precisa ser amadurecida, inclusive problematizando a existência ou não de possibilidade de diálogo de suas com as demandas locais - escola, comunidade e estudantes.

O reconhecimento do processo saúde-doença como complexo e multifatorial implica em assumir a necessidade de abordagens interdisciplinares para garantir maior eficiência das ações. Neste sentido, a questão da formação, recomendação recorrente nos artigos, deve ser aprofundada nos debates sobre com quem e quais focos e intencionalidade são propostos programas de formação em saúde escolar e mais ainda para atuação em estratégias de promoção da saúde na escola. Importante registrar que, por princípio, estratégias educativas desenvolvidas sob a ótica da promoção da saúde sempre intencionam fortalecer a autonomia, o empowerment e têm como ponto de partida o diagnóstico local e a valorização das diferentes potencialidades e saberes.

Nas experiências de EPS identifica-se que em diversos países as atividades relacionadas à avaliação clínica, oftalmológica, odontológica, nutricional, auditiva/fonoaudiológica estão presentes e os professores são citados como responsáveis por parte destas atividades. Eles estão envol- 
vidos na detecção precoce de problemas de comportamento, dificuldades de aprendizado ou doenças físicas; avaliação de peso e altura, ou triagem visual ou auditiva; programas de prevenção de drogas e de violência e de educação sexual ${ }^{4}$. Um reflexo disto aparece nas conclusões de parte dos artigos que recomenda a realização de capacitação de professores nestas áreas especificas.

Não se pretende desviar as funções dos professores e dos profissionais da saúde, mas sim incorporar no âmbito escolar atitudes e práticas que valorizem a promoção da saúde de forma crítica. A ideia é que as questões de saúde não passem despercebidas nesse ambiente, como se apenas os profissionais da saúde soubessem e pudessem dar conta de lidar com elas, desconsiderando as possibilidades de práticas integradas e intersetoriais ${ }^{20}$.

A participação da família e da comunidade nas ações de saúde escolar faz parte do repertório de ações tanto de estratégias pautadas pela higiene escolar quanto de promoção da saúde. No primeiro caso com ênfase na responsabilização e muitas vezes culpabilização dos sujeitos por sua saúde e a de seus familiares e no segundo a partir de um discurso mais democrático.

Para Valla ${ }^{30}$ a participação popular é termo ambíguo que na América Latina encontra contornos autoritários em que grupos conservadores e também muitos progressistas assumem como objetivo o controle das populações da periferia para pôr em prática suas concepções. Neste sentido, sempre que se fala de participação popular em projetos deve-se ter em mente a seguinte questão: de que participação popular está se falando?

As definições necessárias para efetivar intersetorialidade, interdisciplinaridade e participação não ocorrem no vazio, mas contextualizadas pela realidade socioeconômica e política em nível micro e também macro. Isto quer dizer que será necessário compreender em que realidade as estratégia e as políticas públicas de saúde escolar estão sendo engendradas, ou seja, o quanto é um contexto democrático, participativo, popular ou seus contrários. Os limites e as possibilidades de vivenciar efetivamente o conceito ampliado de saúde também estão relacionados ao contexto.

Dentre as diferentes experiências apresentadas nos artigos chama a atenção o número reduzido de ações de promoção de práticas contextualizadas. Identificaram-se artigos que trabalharam questões teóricas relevantes e sugestões possíveis relacionadas ao aprimoramento das ações de saúde escolar nesta direção. Experiências como as descritas, por exemplo, por Hernández ${ }^{21}$, Kornblit et al. ${ }^{24}$, Beserra et al. ${ }^{31}$ e Rabell e Anderson ${ }^{32}$ também apresentam possibilidades e desafios. Sobretudo os debates e relatos que utilizaram o referencial das EPS guardam características de valorização da contextualização, da participação e do apoderamento. Neste sentido, sinalizam propostas viáveis e promissoras para o desenvolvimento de práticas promotoras de saúde na escola.

As reflexões de Dutta-Bergman ${ }^{33}$ relacionadas à comunicação em saúde podem contribuir com este debate. A autora ressalta que nas últimas décadas tem sido reconhecida a centralidade da cultura e a importância de abordagens contextualizadas no que se refere às iniciativas de comunicação em saúde, sobretudo quando se trata da atuação junto a populações marginalizadas. Estas abordagens problematizam os significados atribuídos à saúde e desta forma propõem caminhos alternativos àqueles centrados no discurso rigidamente técnico e científico. Aponta também para a necessidade de incluir as vozes silenciadas das populações marginalizadas. Para além das práticas, Dutta-Bergman ${ }^{33}$ sugere uma "epistemologia das margens" e inversão dos fluxos tradicionais de comunicação que ocorrem em mão única: do centro para a periferia. $\mathrm{O}$ autor reforça a perspectiva de que promover saúde em áreas periféricas é ter como foco a construção de capacidades que se relacionam não apenas à comunicação, mas ao acesso a recursos fundamentais à vida como alimentação, vestuário e moradia.

\section{Considerações finais}

Desde a década de 1990 a promoção de saúde na escola tem sido afirmada e apoiada por organismos internacionais como estratégia de eleição para a saúde escolar na Região. Os debates e as experiências reunidos nos últimos anos demonstram dificuldades e desafios para a efetivação dos aspectos conceituais e políticos proposto pela EPS, mas ao mesmo tempo trazem novas luzes e possibilidades para sua realização.

O cenário latino-americano revela a persistência de iniciativas centradas na doença e em suas formas de transmissão, de ações de triagens e de construção de perfis epidemiológicos e de estratégias educativas relacionadas à transmissão de conhecimentos sobre prevenção, higiene e primeiros socorros. Em grande medida têm sido atividades que, desconsiderando o contexto local e o espaço da vida, apresentam uma lista de regras de controle de risco nem sempre possíveis 
de serem vivenciadas que acabam por culpabilizar a população pelo seu não cumprimento.

As respostas de como enfrentar realidades com suas adversidades, precariedades e riscos à saúde, certamente não está sob o domínio de nenhum profissional isoladamente por mais bem intencionado que esteja. Na verdade, ainda que uma parte da resposta possa estar com os profissionais de saúde e educação em suas diversas especialidades, com certeza parcela importante e essencial encontra-se com os estudantes, as famílias e a comunidade. Trata-se, portanto de um campo interdisciplinar complexo e desafiador.

A efetivação da saúde escolar como política pública de promoção da saúde e de garantia de qualidade de vida exige coordenação e planejamento intersetoriais, com definição de orçamento adequado e coerente com o discurso construído acerca de uma noção ampliada de saúde e de uma educação integral que vem sendo produzido e divulgado na Região. Requer a definição de iniciativas interdisciplinares selecionadas a partir de diagnóstico local da realidade, com identificação dos problemas reais e das soluções viáveis em cada escola de forma a contribuir para a autonomia e o apoderamento dos sujeitos diante dos direitos fundamentais relacionados ao tema da saúde escolar: direito à saúde, à educação, à alimentação e à vida digna.

\section{Colaboradores}

JP Casemiro, ABC Fonseca, FVM Secco participaram da concepção do artigo. JP Casemiro redigiu a primeira versão do artigo, que recebeu contribuição dos outros autores. Todos os autores revisaram e aprovaram a versão final.

\section{Referências}

1. Gomes CM, Horta NC. Promoção da saúde de adolescentes em âmbito escolar. Rev APS 2010; 13(4): 486-499.

2. Descritores em Ciências da Saúde. [acessado em 2013 jan 12]. Disponível em: http://decs.bvs.br/cgi-bin/ wxis1660.exe/decsserver/.

3. Figueiredo TAM, Machado VLT, Abreu MMS. A saúde na escola: um breve resgate histórico. Cien Saude Colet 2010; 15(2):397-402.

4. Ippolito-Shepherd J. Escolas Promotoras de SaúdeFortalecimento da Iniciativa Regional. Estratégias e linhas de ação 2003-2012. Washington: Organização Pan-americana de Saúde (OPAS); 2006.

5. Programa das Nações Unidas para o Desenvolvimento (PNUD); Comissão Econômica para a América Latina e o Caribe (CEPAL), Instituto de Pesquisa Econômica Aplicada (IPEA). Rumo ao Objetivo do Milênio de Reduzir a Pobreza na América Latina e o Caribe. Santiago de Chile: Publicação das Nações Unidas; 2003.

6. Castro MLS. A educação na América Latina: Antigos dilemas em novo contexto. Rev Educação 2008; 31(2):182-188.
7. Salvat P, Román MY, García-Huidobro JE. Horizonte normativo para una educación justa en sociedades democráticas. Una reflexión desde América Latina. Rev Internacional de Educación para la Justicia Social (RIEJS) [Periódico na Internet] 2012 [acessado 2013 jan 20]; 1(1): 46-78. Disponível em: http:/ /www.rinace.net/riejs/numeros/vol1-num1/ art2.pdf.

8. Deslandes SF. O projeto de pesquisa como exercício científico e artesanato intelectual. In: Delandes SF, Minayo MCS, organizadores. Pesquisa social: teoria, método e criatividade. Petrópolis: Vozes; 2012. p. 31-60.

9. Minayo MCS. Fase exploratória da pesquisa. In: Minayo MCS, organizadora. O desafio do conhecimento: pesquisa qualitativa em saúde. São Paulo, Rio de Janeiro: Hucitec, Abrasco; 1996. p. 89-104.

10. Brasil. Portaria Interministerial no 749 , de 13 de maio de 2005. Constitui a Câmara Intersetorial para a elaboração de diretrizes com a finalidade de subsidiar a Política Nacional de Educação em Saúde na Escola. Diário Oficial da União 2005; 18 maio. 
11. Brasil. Decreto Presidencial no 6.286, de 5 de dezembro de 2007. Institui o Programa Saúde na Escola - PSE, e dá outras providências. Diário Oficial da União 2007; 6 dez.

12. Brasil. Lei no 11.947 , de 16 de junho de 2009. Dispõe sobre o atendimento da alimentação escolar e do Programa Dinheiro Direto na Escola aos alunos da educação básica; altera as Leis nos 10.880 , de 9 de junho de 2004, 11.273, de 6 de fevereiro de 2006, 11.507, de 20 de julho de 2007; revoga dispositivos da Medida Provisória no 2.178-36, de 24 de agosto de 2001, e a Lei no 8.913, de 12 de julho de 1994; e dá outras providências. Diário Oficial da União 2007; 17 jun.

13. Freire P. Pedagogia da autônima: saberes necessários à prática educativa. São Paulo: Paz e Terra; 1996.

14. Höfling EM. Estado e políticas (públicas) sociais. Caderno Cedes 2001; 55:30-41.

15. Buss PM. Promoção da Saúde e qualidade de vida. Cien Saude Colet 2000; 5(1):163-177.

16. Arouca ASS. O dilema preventivista: contribuições para a compreensão crítica da medicina preventiva [tese]. Campinas: Faculdade de Ciências Médicas da Universidade Estadual de Campinas; 1975.

17. Larocca LM, Marques VRB. Higienizar, cuidar e civilizar: o discurso médico para a escola paranaense (1920-1937). Interface (Botucatu) 2010; 14(35): 753-766.

18. Zucoloto PCSV. O médico higienista na escola: as origens históricas da medicalização do fracasso escolar. Revista Brasileira de Crescimento e Desenvolvimento 2007; 17(1):136-145.

19. Moysés MAA, Collares CAL. Inteligência abstraída, crianças silenciadas: as avaliações de inteligência. Psicologia USP 1997; 8(1):63-89.

20. Santos KF, Bógus CM. A percepção de educadores sobre a escola promotora de saúde: um estudo de caso. Revista Brasileira de Crescimento e Desenvolvimento 2007; 17(3):123-133.

21. Hernández J. Estrategia escuelas promotoras de la salud en instituciones de básica primaria de Bucaramanga. Revista de la Universidad Industrial de Santander 2007; 39(3):143-151.

22. Organizacion Panamericana de la Salud (OPS) Componentes educativos de los programas para la promocion de la salud escolar. Rev Panam Salud Puública 1997; 2(3):209-214.

23. Cardoso V, Reis AP, Iervolino SA. Escolas promotoras de saúde. Revista Brasileira de Crescimento e Desenvolvimento 2008; 18(2):107-115.

24. Kornblit AL, Diz AMM, Di Leo PF. Camarotti AC. Entre la teoría y la práctica: algunas reflexiones en torno al sujeto en el campo de la promoción de la salud. Rev. argentina de sociologia 2007; 5(8):11-27.
25. Montes GAA, Araujo R, Leontsini E, Herrera GO, Cerna CF. Un programa escolar para el control del dengue en Honduras: del conocimiento a la práctica. Revista Panamericana de Salud Pública 2012; 31(6):518-522.

26. Ferreira IRC, Vosgerau DSR, Moysés SJ, Moysés ST. Diplomas Normativos do Programa Saúde na Escola: análise de conteúdo associada à ferramenta ATLAS TI. Cien Saude Colet 2012; 17(12):3385-3398.

27. Burlandy L. A construção da política de segurança alimentar e nutricional no Brasil: estratégias e desafios para a promoção da intersetorialidade no âmbito federal de governo. Cien Saude Colet 2009; 14(3): 851-860.

28. Molineri MF, Esmoris AL, García M, La-Greca N, Perez C, Brudnick G, Rojas MS, Etchandy P. Algunas reflexiones sobre las representaciones sociales y prácticas de los profesionales de salud escolar. Anu. Investig 2009; 16:231-237.

29. Choque-Larrauri R, Chirinos-Cáceres JL. Eficacia del Programa de habilidades para la vida en adolescentes escolares de Huancavelica, Perú. Revista de Salud Pública 2009; 11(1):169-181.

30. Valla VV. Sobre participação popular: uma questão de perspectiva. Cad Saude Publica 1998; 14(2):7-18.

31. Beserra EP, Araujo MFM, Barroso MGT. Promoção da saúde em doenças transmissíveis: uma investigação entre adolescentes. Acta paul. Enferm 2006; 19(4):402-407.

32. Rabello N, Anderson NIP. Hábitos alimentares e prática de atividade física em escolares: relato de uma experiência de educação em saúde. Rev APS 2011; 14(2):239- 249.

33. Dutta-Bergman MJ. Poverty, Structural Barriers, and Health: A Santali Narrative of Health Communication. Qualitative Health Research 2004; 14(8):11071122.

Artigo apresentado em 15/12/2012

Aprovado em 21/02/2013

Versão final apresentada em 16/03/2013 